\title{
Pemanfaatan Teknologi Informasi dan Komunikasi (TIK) dalam Pembelajaran
}

\author{
Oleh: \\ Zeni Gunawan, M.Pfis \\ Fakultas Tarbiyah dan Keguruan, IAIN Raden Intan Lampung
}

\section{PENDAHULUAN}

Teknologi informasi dan komunikasi (TIK) adalah sesuatu teknologi baik perangkat keras (hardware) maupun perangkat lunak (software) yang digunakan untuk mengelola data/informasi dan komunikasi. Dalam prakteknya teknologi diwakili oleh komputer (perangkat keras) dan program-program aplikasi (perangkat lunak). Data/informasi yang dikelola dan dihasilkan dalam bentuk berbagai media, seperti teks, grafik, gambar diam, foto, film, animasi, dan simulasi. Cara-cara berkomunikasinya memungkinkan untuk dilakukan secara maya.

Wardana (2002) mengemukakan bahwa dalam kehidupan kita di masa mendatang, sektor teknologi informasi dan telekomunikasi merupakan sektor yang paling dominan. Siapa saja yang menguasai teknologi ini, maka dia akan menjadi pemimpin dalam dunianya. Teknologi informasi banyak berperan dalam berbagai bidang termasuk bidang pendidikan.

Perkembangan TIK telah memberikan pengaruh terhadap dunia pendidikan khususnya dalam proses pembelajaran. Menurut Rosenberg (2001) dalam Surya (2006) setidaknya ada lima pergeseran dalam proses pembelajaran yaitu: (1) dari pelatihan ke penampilan, (2) dari ruang kelas ke di mana dan kapan saja, (3) dari kertas ke "online” atau saluran, (4) fasilitas fisik ke fasilitas jaringan kerja, (5) dari waktu siklus ke waktu nyata. Interaksi antara guru dan siswa tidak hanya dilakukan melalui hubungan tatap muka tetapi juga dilakukan dengan menggunakan media-media tersebut. Guru dapat memperoleh informasi dalam lingkup yang luas dari berbagai sumber melalui cyber space atau ruang maya dengan menggunakan komputer atau internet.

\section{PEMBAHASAN}

\section{A. Potensi Teknologi Informasi dan Komunikasi (TIK) dalam Pembelajaran}

Hartono (2004) mengemukakan bahwa dengan TIK peningkatan mutu pendidikan dimungkinkan dengan munculnya berbagai kesempatan baru seperti: 
1. Cara belajar baru bagi peserta didik, dimana mereka bisa lebih mandiri dengan adanya ketersediaan informasi yang melimpah di dunia internet.

2. Kolaborasi akademik yang jauh lebih luas, dimana seorang murid di Indonesia memungkinkan untuk ikut mengakses kelas serupa di luar negeri.

3. Interaksi antara pendidik dengan peserta didik yang lebih beragam, tidak sekedar lewat kelas konvensional, walaupun interaksi lewat kelas fungsional masih jadi mode utama.

4. Interaksi antar pendidik yang juga semakin terbuka kesempatannya. Pendidik di Indonesia bisa saling bertukar informasi dan berkolaborasi sesuai bidangnya masing-masing, bahkan tidak tertutup kemungkinan berkolaborasi dengan komunitas pendidik di luar negeri.

Di samping itu, proses belajar mengajar (PBM) seringkali dihadapkan pada materi yang abstrak dan di luar pengalaman siswa sehari-hari, sehingga materi ini menjadi sulit diajarkan guru dan sulit dipahami siswa. Visualisasi adalah salah satu cara yang dapat dilakukan untuk mengkonkritkan sesuatu yang abstrak. TIK akan dengan mudah memvisualisasikan dalam bentuk gambar bergerak (animasi) yang juga dapat ditambahkan suara. Sajian audio visual yang dikenal dengan multimedia ini akan menjadikan visualisasi menjadi lebih menarik.

\section{B. Pemanfaatan Komputer dalam Pembelajaran}

Kegiatan pembelajaran dengan menggunakan komputer dibagi menjadi 2 yaitu yang pertama disebut dengan Computer Based Instruction (CBI) merupakan istilah umum untuk segala kegiatan belajar yang berbasis pada komputer, baik sebagian maupun keseluruhan. Kedua adalah CAI (Computer Assisted Instruction), yaitu pembelajaran dengan menggunakan alat bantu komputer, seperti untuk presentasi, sebagai alat peraga dan sebagainya.

Rusman (geocities.com) mengemukakan bahwa media dalam pembelajaran memiliki fungsi sebagai alat bantu untuk memperjelas pesan yang disampaikan guru. Media juga berfungsi untuk pembelajaran individual dimana kedudukan media sepenuhnya melayani kebutuhan belajar siswa. Beberapa bentuk penggunaan komputer media yang dapat digunakan dalam pembelajaran meliputi: (1) Penggunaan multimedia presentasi, (2) Multimedia interaktif, dan (3) Pemanfaatan Internet dalam pembelajaran. Aplikasi komputer dalam bidang pembelajaran 
memungkinkan berlangsungnya proses belajar secara individual (individual learning). Pemakai komputer atau user dapat melakukan interaksi langsung dengan sumber informasi. Perkembangan teknologi komputer jaringan (computer network/internet) saat ini telah memungkinkan pemakainya melakukan interaksi dalam memperoleh pengetahuan dan informasi yang diinginkan. Berbagai bentuk interaksi pembelajaran dapat berlangsung dengan tersedianya medium komputer.

Masrur (2007) mengemukakan bahwa bila sekolah akan menerapkan model pembelajaran berbasis komputer, maka langkah yang dapat dilakukan antara lain:

\section{Peningkatan kapasitas kelembagaan}

Perlu disadari bahwa untuk meningkatkan kapasitas kelembagaan diperlukan pemahaman konsep dasar pemberdayaan. Konsep ini harus dilandasi dengan nilainilai prinsip dan nilai-nilai instrumental yang selanjutnya tumbuh secara sadar dalam jiwa para warga sekolah, sehingga dalam diri warga sekolah muncul kesadaran diri, kesadaran kolektif, dan kesadaran lingkungan fisik yang berkelanjutan.

\section{Pengajaran dan pembelajaran berbasis komputer}

Dalam upaya mengoptimalkan penguasaan siswa terhadap bahan ajar perlu diputuskan model pembelajaran yang bermakna dan dapat melatih kemampuan siswa untuk berfikir dan berbuat. Faktor yang menjadi titik lemah adalah pemahaman dan kemampuan guru dalam mengoperasikan komputer, sehingga guru perlu diberi pelatihan sampai setidaknya cukup terampil dalam mengoperasikan komputer

\section{Pengadaan sarana prasarana komputer}

Dalam rangka mendukung kegiatan pembelajaran yang menggunakan komputer, sarana prasarana menjadi kendala karena minimnya sarana prasarana tersebut. Oleh karenanya bantuan pemerintah maupun masyarakat senantiasa menjadi dambaan pihak sekolah.

\section{Penggunaan Multimedia dalam Pembelajaran}

Menurut Hartono (2004), multimedia pembelajaran adalah segala sesuatu yang digunakan untuk menyalurkan pesan (pengetahuan, keterampilan, dan sikap), serta dapat merangsang pikiran, perasaan, perhatian dan kemauan sehingga secara sengaja proses belajar terjadi, bertujuan, dan terkendali. Menurutnya, ada enam komponen media yang dapat dikategorikan multimedia pembelajaran, yaitu: teks, grafik, foto, video, suara, animasi/simulasi. 
Nurtjahjawilasa (2004) mengemukakan bahwa multimedia mempunyai peranan semakin penting dalam pembelajaran. Banyak orang percaya bahwa multimedia akan dapat membawa kita kepada situasi belajar dimana "learning with effort” akan dapat digantikan dengan "learning witf fun”. Jadi proses pembelajaran yang menyenangkan, kreatif, tidak membosankan menjadi pilihan para fasilitator.

Kapan multimedia efektif dapat digunakan dalam pembelajaran? Untuk menjawabnya perlu memahami level-level multimedia yang menurut Mayer (2001), mempunyai tiga level yaitu:

1. Level teknis, yaitu multimedia berkaitan dengan alat-alat teknis; alat-alat ini dapat diartikan sebagai wahana yang meliputi tanda-tanda (sign).

2. Level semiotik, yaitu representasi hasil multimedia seperti teks, gambar, grafik, tabel, dll.

3. Level sensorik, yaitu yang berkaitan dengan saluran sensorik yang berfungsi untuk menerima tanda (sign).

Dengan memanfaatkan ketiga level di atas diharapkan kita dapat mengoptimalkan multimedia dan mendapatkan efektivitas pemanfaatan multimedia dalam proses pembelajaran.

Dalam membuat suatu multimedia pembelajaran, tidak harus seluruh media ditampilkan. Penggunaan media yang kurang tepat justru akan mengaburkan konten yang ingin disampaikan. Pemilihan jenis media yang digunakan tergantung pada konten materi yang disajikan, karena setiap media memiliki karakteristik masingmasing. Jenis multimedia dalam pembelajaran meliputi:

\section{Multimedia Presentasi}

Multimedia presentasi digunakan untuk menjelaskan materi-materi yang sifatnya teoritis, digunakan dalam pembelajaran klasikal dengan kelompok belajar yang cukup banyak. Media ini cukup efektif sebab menggunakan multimedia proyektor yang memiliki jangkauan pancar cukup besar. Kelebihan media ini adalah menggabungkan semua unsur media seperti teks, video, animasi, image, grafik dan sound menjadi satu kesatuan penyajian, sehingga mengakomodasi sesuai dengan modalitas belajar siswa. Program ini dapat mengakomodasi siswa yang memiliki tipe visual, auditif maupun kinestik(Rusman, geocities.com).

\section{Multimedia interaktif}


Menurut Rusman (geocities.com) diperkuat Samsudin (2008), CD interaktif merupakan media yang bersifat interaktif dan multimedia karena terdapat unsurunsur media secara lengkap meliputi sound, animasi, video, teks dan grafis.

Beberapa model multimedia interaktif yaitu: (1) Model Drill: merupakan salah satu strategi pembelajaran yang bertujuan memberikan pengalaman belajar yang lebih konkrit melalui penciptaan tiruan-tiruan bentuk pengalaman yang mendekati suasana sebesarnya (biasanya dalam bentuk latihan soal-soal), (2) Model Tutorial: merupakan program pembelajaran dengan menggunakan perangkat lunak berupa program komputer yang berisi tujuan, materi pelajaran dan evaluasi, (3) Model Simulasi: pengajaran dengan komputer untuk simulasi pada suatu keadaan khusus, atau sistem di mana siswa dapat berinteraksi, (4) Model Games: model permainan ini dikembangkan berdasarkan atas ”pembelajaran yang menyenangkan”, dimana peserta didik akan dihadapkan pada beberapa petunjuk dan aturan permainan.

Kehadiran multimedia pembelajaran dirasakan banyak membantu tugas guru dalam mencapai tujuan pembelajarannya. Namun demikian terdapat beberapa tantangan yang muncul sebagai akibat penerapan teknologi tersebut dalam bidang pendidikan yaitu (Payong, sinarharapan.co.id):

1. Orientasi filisofis: Kelompok objektivitas memandang multimedia sebagai sesuatu yang sangat riil yang dapat membantu pendidikan siswa menuju kepada tujuan yang diharapkan. Sebaliknya kelompok kontruktivis memandang bahwa pengetahuan hendaklah dibentuk oleh siswa sendiri berdasarkan penafsirannya terhadap pengalaman dan gejala hidup yang dialami. Berdasarkan pandangan ini maka belajar bersifat aktif, kolaboratif dan terkondisi dalam konteks dunia yang riil.

2. Lingkungan belajar: Lingkungan belajar multimedia interaktif dapat dikategorikan menjadi prespektif, demokratis, dan sibermetik. Lingkungan prespektif menekankan pada prestasi belajar merupakan pencapaian dari tujuan-tujuan belajar yang ditetapkan secara eksternal. Lingkungan demokratis menekankan pada kontrol proaktif siswa atas proses belajarnya sendiri. Sedangkan lingkungan sibermetik menekankan pada saling ketergantungan antara sistem balajar dan siswa.

3. Desain Instruksional: Pada umumnya desain pembelajaran multimedia dibuat berdasarkan besar kecilnya kontrol siswa atas pembelajarannya. Sebagian besar peneliti mengatakan bahwa siswa bisa diberdayakan melalui kontrol yang lebih besar atas belajarnya tetapi siswa bisa juga dihambat melalui kontrol atas belajarnya. 
4. Umpan balik: Sifat dari umpan balik dalam pembelajaran multimedia sangat bevariasi tergantung pada lingkungan di mana multimedia itu digunakan. Jadi bentuk umpan balik harus sesuai dengan lingkungan belajarnya.

5. Sifat sosial: Banyak kritik telah dilontarkan terhadap pembelajaran multimedia sebagai pembelajaran yang bersifat isolatif sehingga bertentangan dengan tujuan sosial dari sekolah. Siswa seolah-olah dikondisikan untuk menjadi individualisindividualis dan kontak sosial dengan teman-teman menjadi sesuatu yang asing.

\section{Pemanfaatan Internet dalam Pembelajaran}

Internet, singkatan dari interconection and networking, adalah jaringan informasi global, yaitu "the largest global network of computers, that enables people throughout the world ti conent with each other". Rusman (geocities.com) mengemukakan bahwa pemanfaatan internet sebagai media pembelajaran mengkondisikan siswa untuk belajar mandiri. Para siswa dapat mengakses secara online dari berbagai perpustakaan, museum, database, dan mendapatkan sumber primer tentang berbagai peristiwa sejarah, biografi, rekaman, laporan, data statistik. Siswa dapat berperan sebagai seorang peneliti, menjadi seorang analis, tidak hanya konsumen informasi saja. Mereka menganalisis informasi yang relevan dengan pembelajaran dan melakukan pencarian yang sesuai dengan kehidupan nyata (real life). Siswa dan guru tidak perlu hadir secara fisik di kelas (classroom meeting), karena siswa dapat mempelajari bahan ajar dan mengerjakan tugas-tugas pembelajaran serta ujian dengan cara mengakses jaringan komputer yang telah ditetapkan secara online. Siswa juga dapat belajar bekerjasama (collaborative) satu sama lain. Mereka dapat saling berkirim e-mail (electronic mail) untuk mendiskusikan bahan ajar. Selain mengerjakan tugas-tugas pembelajaran dan menjawab pertanyaan-pertanyaan yang diberikan guru, siswa dapat berkomunikasi dengan teman sekelasnya (classmaters).

Siahaan (tekkomdik-sumbar.org) dari hasil kajiannya mengemukakan bahwa para peserta didik dan guru menyambut positif gagasan untuk merintis penyelenggaraan pembelajaran berbasis internet, masalahnya adalah apa yang perlu dilakukan sehingga fasilitas internet dapat dimanfaatkan secara optimal untuk kepentingan pendidikan/pembelajaran yang pada akhirnya akan dapat meningkatkan kualitas hidup bangsa Indonesia. Bahan pembelajaran elektronik dikemas dan dimasukkan ke dalam jaringan sehingga dapat diakses melalui internet. Kegiatan berikutnya yang perlu dilakukan adalah mensosialisasikan ketersediaan program pembelajaran tersebut agar 
diketahui oleh masyarakat khususnya para peserta didik. Para guru perlu diberikan pelatihan agar mereka mampu mengelola dengan baik penyelenggaraan melalui internet.

\section{E. Etika dan Moral dalam Penggunaan TIK}

Etika dan moral harus mendapat perhatian yang serius dalam penggunaan TIK. Komputer (hardware) dan perangkat lunaknya (sofware) adalah orientasi utama dari TIK. Perangkat lunak atau software program komputer merupakan hasil dari pemikiran dan budidaya manusia, dan dalam TIK perangkat lunak ini adalah produk paling dihargai karena berkaitan dengan hakikat dan kekuatan hukum kepemilikan. Dalam menciptakan suatu hasil karya yang baru, perlu adanya perlindungan hukum dari tindakan ilegal (misalnya pembajakan). Dalam hal perlindungan hukum tersebut perlu ditekankan masalah: (1) hak paten, (2) merek dagang, (3) paten, (4) desain produk industri, (5) indikasi geografi, (6) layout desain, (7) perlindungan informasi rahasia, dll.

Di sisi lain dengan mengunakan internet, kita dengan mudah mendapatkan informasi apapun (baik dan buruk) dari seluruh penjuru dunia. Bila dimanfaatkan dengan benar, maka layanan tersebut dapat digunakan sebagai sumber ilmu. Tetapi jika disalah gunakan untuk hal-hal yang negatif, maka dampak negatifnya tidak kalah dasyat dibandingkan dampak positifnya. Keberadaan situs-situs amoral misalnya akan sangat buruk dampaknya jika diakses oleh anak-anak. Sangatlah tepat jika pemerintah akan melakukan pemblokiran situs amoral yang masuk ke Indonesia bekerjasama dengan jaringan provider. Menurut Muhammad Nuh (Menkominfo) yang dikutif Sundiawan (OkeZone.com) ”Sebenarnya, konsep dasar program ini untuk menumbuhkan kesadaran pada individu. Kuncinya disitu. Jadi, setiap pribadi memiliki filtering dan bisa melakukan sendiri”. Oleh karenanya yang terpenting adalah tumbuhnya kesadaran masyarakat untuk dapat memanfaatkan keberadaan internet tersebut untuk hal yang positi

\section{KESIMPULAN}

Perkembangan TIK telah memberikan pengaruh terhadap dunia pendidikan khususnya dalam proses pembelajaran. Menurut Rosenberg (2001) dalam Surya (2006) setidaknya ada lima pergeseran dalam proses pembelajaran yaitu: (1) dari pelatihan ke penampilan, (2) dari ruang kelas ke di mana dan kapan saja, (3) dari kertas ke "online” atau saluran, (4) fasilitas fisik ke fasilitas jaringan kerja, (5) dari waktu siklus ke waktu nyata. Interaksi antara guru dan siswa tidak hanya dilakukan melalui hubungan tatap 
muka tetapi juga dilakukan dengan menggunakan media-media tersebut. Guru dapat memperoleh informasi dalam lingkup yang luas dari berbagai sumber melalui cyber space atau ruang maya dengan menggunakan komputer atau internet.

\section{DAFTAR PUSTAKA}

Gijselaers, W.H. 1996. Connecting Problem-Based Practices with Educational Theory. NeDiection for Teaching and Learning No. 68. p. 13-21. Jossey Bass Publisher.

Hardjito. 2005. Jurnal Internet untuk Pembelajaran, www.pustekkom.go.id. Diakses 21 Juli 2006.

Ibrahim, M., \& Nur, M. 2004. Pembelajaran Berdasar-kan Masalah.Unesa-University Press. Surabaya.

LaWson, A.E. 1998. Science Teaching and The Develop-ment of Thinking. California:Wadworth Publish-ing Company.

Liu, M. 2005. Alien Rescue: A Problem-Based Learning Environment for Middle School Science. http: //tip.missouri.edu/tip.nsf/0/D03C1427DD93E76F86256BE7007FB59F? OpenDocument. Diakses 3 Juni 2006.

McKnight, C. \& Dillon, A. 1996. User Centered Design Hypertext/Hypermedia for Education. Handbook of Research for Educational Communication and Technology, ed. David H. Jonassen. London : Prentice Hall International.

Novak, J.D. \& Gowin.D.B.1985. Learning How to Learn. New York: Cambride University Press.

Santyasa, I.W, Suwindra, I N.P, Sujanem, R., \& Suardana, K. 2005. Pengembangan Teks Fisika Bermuatan Model Perubahan Konseptual dan Komunitas Belajar Serta Pengaruhnya terhadap Perolehan Kompetensi Siswa Kelas I di SMU. Laporan Penelitian. RUKK Tahun I 2005.

Suwindra, I.N.P. 2004. Penerapan Model Pembelajaran Fisika Interaktif Berbasis Web di Kelas I SMU Negeri 1 Bandar Lampung. Jurnal Pendidikan dan Pengajaran No 3 Th XXXVII Juli 2004 hal. 85-95.

Turner, S. V., \& Handler, M. G. 1997. Hypermedia in Education: Children as Audience or Authors? Journal of Information Technology for Teacher Education, 6 (1), 25-35.

Theyßen, H. 2006. Students' Attitudes Towards The Hypermedia Learning Environment "Physics for Medical Students" [Online]. EURODOL. Terse-dia:[http://www.idn.unibremen.de/] Diakses 15 April 2006.

Williams, D.C., Pedersen, S., \& Liu, M. 1998. An Evaluation of the Use of Problem-Based Learning Software By Middle School Students. Journal of Universal Komputer Science vol 4 issue 4 hal 466-483. 